\title{
El estudio de la distrofia muscular de Duchenne: más allá del ángulo médico
}

\author{
The study of Duchenne muscular dystrophy: beyond the medical angle
}

\begin{abstract}
Resumen
La distrofia muscular de Duchenne (DMD) es una enfermedad neuromuscular hereditaria y degenerativa que afecta a uno por cada 3500 a 6000 varones recién nacidos. Se ha estudiado principalmente desde una perspectiva médica. Se realizó una revisión narrativa con el objetivo de analizar algunos estudios que abordan la DMD desde una perspectiva psicosocial, incluidos los temas de interés, dónde, quién y cómo se ha estudiado, además de qué modelos de la discapacidad subyacen a los estudios. El desgaste de los cuidadores y la afectación en la calidad de vida de personas con DMD son los temas más estudiados, el uso de metodologías cuantitativas las más comunes, y el modelo biopsicosocial el más presente. La mayoría de los estudios se realizaron en países del primer mundo. Aún es limitada la literatura que alude a un modelo social, pero logra vislumbrarse ya la necesidad de ampliar el abordaje de la DMD.
\end{abstract}

\section{Palabras clave}

Distrofia muscular de Duchenne, DMD, discapacidad, modelos de la discapacidad, aspectos psicosociales.

\begin{abstract}
Abtract
Duchenne muscular dystrophy (DMD) is a hereditary neuromuscular degenerative disorder that affects between one in 3,500 to one in 6,000 newborn males. It has been studied mainly from a medical perspective. A narrative review was performed with the objective of analysing some studies that tackled DMD from a psychosocial perspective, focusing on the themes: where, who, and how they have been studied, and their underlying disability models. The caregiver burnout and the effect on the quality of life of people with DMD are the most studied themes. The use of quantitative methods is the most common one and the biopsychosocial model, the most used one. The majority of these studies where performed in first world countries. Literature referring to a social model is still limited, but enough to give a glimpse of the need to increase the social research of DMD.
\end{abstract}

\section{Keywords}

Duchenne muscular dystrophy, DMD, disability, models of disability, psychosocial aspects.

\section{Cintia Aguilar-Delgadillo <cintiaguilar@gmail.com>}

Universidad Nacional Autónoma de México. México

\section{Luciana Ramos-Lira \\ <ramos|@imp.edu.mx>}

Instituto Nacional de Psiquiatría 'Ramón de la Fuente Muñiz'. México

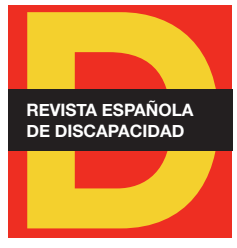

Para citar:

Aguilar-Delgadillo, C. y Ramos-Lira, L. (2020). "El estudio de la distrofia muscular de Duchenne: más allá del ángulo médico". Revista Española de Discapacidad, 8(I), pp. 181-200.

Doi: <https://doi.org/10.5569/23405104.08.01.10>

Fecha de recepción: 07-01-2019 Fecha de aceptación: 12-05-2020 


\section{Introducción ${ }^{1}$}

La distrofia muscular de Duchenne (DMD) es una enfermedad incurable, progresiva, discapacitante y letal (Fee y Hinton, 2011; Landfeldt et al., 2016), que degenera el músculo esquelético y cardiaco. Es de origen genético ligada al cromosoma X recesivo Xp21, también llamado el gen de la distrofina (Singh et al., 2018; Strehle y Straub., 2015). La mutación de este gen, ya sea a través de delecciones, mutaciones puntuales, duplicaciones o inserciones, afecta la codificación de la proteína distrofina, encargada de dar soporte y protección a las células musculares (Astrea et al., 2015; Edwards y Philips, 2016). La ausencia de esta proteína indica que existe una alteración de las fibras musculares que gradualmente serán destruidas, debilitando los músculos y alterando la marcha independiente (Bushby et al., 2010a; Vieitez et al., 2017; Viñas, 2013). Uno de cada tres casos se debe a mutaciones de novo, es decir, no son de carácter hereditario (Giliberto et al., 2014; Huml, 2015; Perumal et al., 2015).

La DMD afecta usualmente a los varones. A nivel mundial tiene una incidencia de entre uno por cada 3500 y uno por cada 6000 varones recién nacidos (Bushby et al., 2010a; Castiglioni et al., 2018; de la Peña et al., 2017; Chaustre y Chona, 2011; Flanigan, 2014). Las mujeres suelen ser portadoras asintomáticas manifestando en muy pocos casos síntomas (Earle y Bebilacqua, 2018; Fraser et al., 2018; Giliberto, et al., 2014; Hayes et al., 2016).

La enfermedad es diagnosticada aproximadamente a la edad de cinco (Edwards y Philips, 2016), pero los síntomas se presentan antes de los cuatro años: debilidad muscular progresiva manifiesta en caídas frecuentes y dificultades para caminar, correr, subir escaleras y levantarse al estar sentados en el piso. La progresión de los síntomas tiene implicaciones en la función locomotora provocando una discapacidad motriz alrededor de los doce años (deja de caminar) o antes si es que no han sido tratados con esteroides (Chaustre y Chona, 2011; Flanigan, 2014; Gutiérrez-Rivas et al., 2014; de la Peña et al., 2017).

Este tipo de distrofia es la más común en niños y suele ser conocida como la distrofia de las infancias (Daack-Hirsch et al. 2013; Mah, 2015; Mah et al., 2016). Sin embargo, esto se ha visto modificado, ya que ante los avances en los tratamientos la esperanza de vida ha aumentado, en promedio las personas con DMD viven 25 años (Eagle et al., 2007; Fokkema et al., 2013). Estudios más recientes señalan que las personas con DMD llegan a vivir más allá de los 30 años (Birnkrant et al., 2018b; Hoskin, 2017; Pangalila et al., 2015b; Ozyurt et al., 2015; Peay et al., 2015). En México, la edad de fallecimiento es menor que en los países desarrollados, ocurriendo aproximadamente a los 19 años (Vázquez-Cárdenas et al., 2013).

La DMD es una enfermedad multisistémica que amerita la competencia de diversas disciplinas y especialidades para su tratamiento, con la finalidad de conservar la funcionalidad (movilidad) del paciente, mejorar su calidad de vida y aumentar su longevidad, ya que hasta el momento no existe alguna cura (Bushby et al., 2010b; Edwards y Philips, 2016; Strehle y Straub, 2015; Vázquez-Cárdenas, et al., 2013; Viñas 2013): pediatras, neurólogos, cardiólogos, genetistas, neumólogos, oftalmólogos, especialistas en rehabilitación física, psicólogos, nutriólogos, gastroenterólogos y ortopedistas son algunos de los especialistas involucrados. Cabe señalar que

1. La revisión narrativa que aquí se presenta forma parte de la tesis doctoral de la primera autora, financiada por el Consejo Nacional de Ciencia y Tecnología (CONACYT). Número de CVU 324001/becario 229932. 
cada caso requiere de una atención específica que quizá demande la competencia de alguna especialidad que aquí no se haya mencionado. Es relevante, además, enfatizar la consideración de los pacientes y sus familiares como parte de los expertos en el monitoreo de la enfermedad, de modo que la colaboración de esfuerzos entre los diversos involucrados favorezca la adaptación de los cuidados y el manejo de la enfermedad a medida que esta progresa, incluyendo el apoyo psicosocial, particularmente el estrés y desgaste que suelen experimentar los cuidadores de personas con DMD (Bushby et al., 2010a; Mah, 2015).

Resulta fundamental entonces, el conocimiento generado desde la perspectiva médica cuyos temas de interés tienen pertinencia y relevancia principalmente para los profesionales de la salud, destacando entre ellos:

- El diagnóstico, enfocado en aspectos bioquímicos y moleculares que contribuyen a identificar el gen y la proteína que están alterados (Coral-Vázquez et al., 2010; González-Huerta et al., 2004; Luna-Ángulo et al., 2016; Vieitez et al., 2017); en identificar posibles portadoras en la familia para prevenir casos futuros (Giliberto et al., 2014; González-Herrera et al., 2009), y en la descripción clínica y patológica de la enfermedad (Bushby et al., 2010a; Cammarata-Scalisi et al., 2008; Singh et al., 2018).

- El tratamiento, centrado en el manejo de las complicaciones en la salud tales como la rehabilitación, la intervención farmacológica y quirúrgica (Birnkrant et al., 2018a, 2018c; Chaustre y Chona, 2011; Strehle y Straub, 2015) por las afectaciones de los huesos - escoliosis - (Flanigan, 2014) y por las complicaciones respiratorias - función pulmonar- (Cruz et al., 2012; Viñas, 2013) y cardiacas (Birnkrant et al., 2018c), ya que éstas últimas suelen ser las causas comunes de fallecimiento. Otros estudios se han interesado en el impacto del tratamiento con glucocorticoides, siendo este el más sugerido por los médicos para conservar la fuerza muscular (McDonald et al., 2013; de la Peña et al., 2017).

Sin embargo, este conocimiento parece no ser suficientemente para dar cuenta de la complejidad de vivir con DMD, ya que las personas diagnosticadas con esta enfermedad no solo se encuentran inmersas en contextos hospitalarios, sino también en contextos sociales. Por ello, surge el interés de conocer cómo se ha estudiado la DMD desde otros ángulos, particularmente desde una perspectiva psicosocial. Se entiende aquí por "aspectos psicosociales" aquellos factores que intervienen en los modos de reaccionar de las personas frente a la enfermedad: sus pensamientos, emociones, comportamientos y sensaciones corporales habituales cuando afrontan un diagnóstico médico y una condición de salud crónica (Turabián y Pérez-Fran$c o, 2014)$. Asumimos que si bien cada vez se utiliza un discurso más cercano a los modelos de corte social, que consideran necesaria la colaboración de esfuerzos y experiencias (Bushby et al., 2010a; Birnkrant et al., 2018b) en la generación del conocimiento, sigue prevaleciendo una visión biomédica que paradójicamente parece muy difícil de desmantelar.

En razón del dominio médico en el abordaje de la DMD y debido a que ésta deriva en una discapacidad motriz evidente de carácter progresivo, hemos recurrido a los modelos de la discapacidad como construcciones sociales que permiten analizar las maneras de entender, explicar y atender la DMD en determinados contextos (Gergen, 1996): (1) el modelo de prescindencia (eugenésico y de marginación); (2) el modelo médico; (3) el modelo social; (4) el biopsicosocial, y (5) el de diversidad funcional. En la tabla 1 se describe el contexto histórico en el que emergió el modelo, las causas atribuidas a la discapacidad, la actitud social subyacente y la consecuente nomenclatura para referirse a las personas con discapacidad, con el fin de dar cuenta de las convergencias y particularidades de cada modelo. 


\begin{tabular}{|c|c|c|c|c|}
\hline \multicolumn{2}{|c|}{$\begin{array}{c}\text { Modelo } \\
\text { (contexto histórico) }\end{array}$} & \multirow{2}{*}{$\begin{array}{l}\begin{array}{c}\text { Causas } \\
\text { atribuidas a la } \\
\text { discapacidad }\end{array} \\
\text { Sobrenaturales } \\
\text { - Embrujo } \\
\text { - Maldición } \\
\text { - Señal de un } \\
\text { mal augurio } \\
\text { - Castigo de los } \\
\text { dioses } \\
\text { - Hechos } \\
\text { astronómicos }\end{array}$} & \multirow{2}{*}{$\begin{array}{l}\text { Supuestos y actitud social } \\
\text { Prescindencia. Los niños que nacen con defectos } \\
\text { deben ser eliminados a través de la muerte para } \\
\text { evitar la imperfección. } \\
\text { Actitud diferenciada ante una discapacidad } \\
\text { producto de una guerra o accidente, siendo la } \\
\text { primera consecuencia de servir a la sociedad. }\end{array}$} & \multirow{2}{*}{$\begin{array}{l}\text { Nomenclatura } \\
\text { para referirse a } \\
\text { las personas con } \\
\text { discapacidad }\end{array}$} \\
\hline \multirow{2}{*}{$\begin{array}{l}\frac{\pi}{0} \\
\frac{C}{0} \\
\frac{D}{0} \\
\frac{.}{0} \\
\Phi \\
\frac{1}{\square}\end{array}$} & $\begin{array}{l}\text { Eugenésico } \\
\text { - Antigüedad } \\
\text { clásica } \\
\text { - Edad Media }\end{array}$ & & & \\
\hline & $\begin{array}{l}\text { Marginación } \\
\text { - Edad Media } \\
\text { - Renacimiento } \\
\text { - Ilustración } \\
\text { - Siglo XIX }\end{array}$ & $\begin{array}{l}\text { Religiosas } \\
\text { - Castigo divino } \\
\text { - Producto de } \\
\text { un pecado } \\
\text { - Voluntad de } \\
\text { Dios }\end{array}$ & $\begin{array}{l}\text { - Marginación. Repulsión, rechazo, aislamiento } \\
\text { y expulsión social hacia a las personas con } \\
\text { carencias físicas y mentales asociado al temor y } \\
\text { peligro; guardados, escondidos en fortalezas y } \\
\text { ciudades amuralladas. } \\
\text { Cuando permanecían en la comunidad eran objeto } \\
\text { de burlas, lástima y compasión, cuyo rol era de: (a) } \\
\text { bufones (objeto de diversión) o mendigos (sujeto } \\
\text { de caridad); (b) consejeros por atribuir mayor } \\
\text { cercanía con Dios. }\end{array}$ & $\begin{array}{l}\text { - } \text { - Mastigadocido } \\
\text { - Impuro } \\
\text { - } \text { Condenado } \\
\text { - Pobre } \\
\text { - Desvalido } \\
\text { - Inferior } \\
\text { - Idiotas de } \\
\text { - nacimiento } \\
\text { - Meforme } \\
\text { - Barginado } \\
\text { - Ser divino } \\
\text { - Mensajero de Dios } \\
\text { - Huérfanos }\end{array}$ \\
\hline \multicolumn{2}{|c|}{$\begin{array}{l}\text { Médico } \\
\text { (Rehabilitador) } \\
\text { Principios del siglo XX }\end{array}$} & $\begin{array}{l}\text { Individuales } \\
\text { Deficiencias o } \\
\text { fallas biológicas } \\
\text { de la persona, } \\
\text { ocasionadas por: } \\
\text { - Enfermedad } \\
\text { - Accidente } \\
\text { - Condición de } \\
\text { salud }\end{array}$ & $\begin{array}{l}\text { - Las deficiencias de un individuo son } \\
\text { susceptibles de ser modificadas (rehabilitadas) } \\
\text { independientemente de su origen. } \\
\text { - Rehabilitar (física, psíquica o sensorial) para curar } \\
\text { las deficiencias, adaptarse a ellas o modificar la } \\
\text { conducta (ocultar/disimular la diferencia). } \\
\text { - Tratamientos individualizados para alcanzar un } \\
\text { funcionamiento "normal". } \\
\text { - Paternalismo y sobreprotección de los } \\
\text { profesionales de salud hacia las personas con } \\
\text { discapacidad. } \\
\text { Las personas con discapacidad deben ser } \\
\text { atendidas en lugares especializados: instituciones } \\
\text { de educación especial y rehabilitación médica. }\end{array}$ & $\begin{array}{ll}\text { - } & \text { Enfermo } \\
\text { - } & \text { Desviado del } \\
& \text { estándar de } \\
& \text { normalidad } \\
\text { - Retrasado mental } \\
\text { - } \text { Minusválido } \\
\text { - Inválido } \\
\text { - Mutilado } \\
\text { - Inútil } \\
\text { - Deficiente } \\
\text { - Discapacitado }\end{array}$ \\
\hline
\end{tabular}




\begin{tabular}{|c|c|c|c|}
\hline $\begin{array}{c}\text { Modelo } \\
\text { (contexto histórico) }\end{array}$ & $\begin{array}{l}\text { Causas } \\
\text { atribuidas a la } \\
\text { discapacidad }\end{array}$ & Supuestos y actitud social & $\begin{array}{l}\text { Nomenclatura } \\
\text { para referirse a } \\
\text { las personas con } \\
\text { discapacidad }\end{array}$ \\
\hline $\begin{array}{l}\text { Social } \\
\text { Finales de la década } \\
\text { de 1960. Movimientos } \\
\text { de vida independiente }\end{array}$ & $\begin{array}{l}\text { Sociales } \\
\text { La discapacidad } \\
\text { es una } \\
\text { construcción } \\
\text { y un modo de } \\
\text { opresión social } \\
\text { que no considera } \\
\text { las necesidades } \\
\text { de todas las } \\
\text { personas } \\
\text { dentro de su } \\
\text { organización }\end{array}$ & $\begin{array}{l}\text { - Se enfatiza la distinción entre: deficiencia } \\
\text { (condiciones biofísicas de carácter individual) } \\
\text { y discapacidad (exclusión de las personas con } \\
\text { discapacidad de la sociedad en general "normal”). } \\
\text { - Su lema es "nada sobre nosotros sin nosotros" } \\
\text { - Las personas con discapacidad aspiran a potenciar } \\
\text { el respeto por la dignidad humana, la igualdad y la } \\
\text { libertad personal; lograr una completa participación } \\
\text { social; eliminar las barreras sociales (segregación) } \\
\text { y equiparar oportunidades (accesibilidad a los } \\
\text { medios humanos y tecnológicos necesarios). } \\
\text { - Las personas con discapacidad reclaman sus } \\
\text { derechos civiles y luchan por tener el control total } \\
\text { sobre dónde y cómo vivir sus vidas. } \\
\text { - Las soluciones deben dirigirse a la sociedad no al } \\
\text { individuo, pero sí deben considerar a las personas } \\
\text { con discapacidad como parte activa para el } \\
\text { cambio. }\end{array}$ & $\begin{array}{l}\text { - Impedido } \\
\text { - Persona } \\
\text { incapacitada } \\
\text { - Persona } \\
\text { discapacitada } \\
\text { - Persona con } \\
\text { deficiencia } \\
\text { - Persona con } \\
\text { discapacidad }\end{array}$ \\
\hline $\begin{array}{l}\text { Biopsicosocial } \\
2001 \text { - Clasificación } \\
\text { Internacional de } \\
\text { Funcionamiento de la } \\
\text { Discapacidad y de la } \\
\text { Salud (CIF) (OMS) }\end{array}$ & $\begin{array}{l}\text { La discapacidad } \\
\text { surge como } \\
\text { una interacción } \\
\text { dinámica entre los } \\
\text { estados de salud } \\
\text { (enfermedades o } \\
\text { trastornos, CIE- } \\
\text { 10) y factores } \\
\text { contextuales } \\
\text { (actitudes } \\
\text { negativas como el } \\
\text { rechazo o barreras } \\
\text { arquitectónicas) }\end{array}$ & $\begin{array}{l}\text { - La discapacidad es un fenómeno universal. } \\
\text { - Es una Integración del modelo médico y el modelo } \\
\text { social. } \\
\text { - estándar y universal que considere las diferentes } \\
\text { dimensiones de la salud. } \\
\text { - Define la discapacidad como "las deficiencias, } \\
\text { limitaciones de la actividad o restricciones en la } \\
\text { participación". } \\
\text { - Permite elaborar un perfil sobre el funcionamiento, } \\
\text { la discapacidad y la salud del individuo en varios } \\
\text { dominios, que indican la magnitud, la ausencia, la } \\
\text { gravedad o la restricción para realizar una función } \\
\text { o actividad (espectro de la discapacidad). }\end{array}$ & $\begin{array}{l}\text { - Persona con } \\
\text { discapacidad } \\
\text { - Persona con } \\
\text { déficit en el } \\
\text { funcionamiento } \\
\text { - Persona con } \\
\text { limitación en la } \\
\text { actividad } \\
\text { - Persona con } \\
\text { restricción en la } \\
\text { participación }\end{array}$ \\
\hline $\begin{array}{l}\text { Diversidad funcional } \\
2005 \text { - Foro de vida } \\
\text { Independiente en } \\
\text { España. }\end{array}$ & $\begin{array}{l}\text { Tiene sus } \\
\text { orígenes en el } \\
\text { Movimiento } \\
\text { de Vida } \\
\text { Independiente. } \\
\\
\text { Desplaza el } \\
\text { problema de } \\
\text { la diversidad } \\
\text { funcional del } \\
\text { individuo al } \\
\text { entorno (modelo } \\
\text { de perfección } \\
\text { y normalidad } \\
\text { impuesto por las } \\
\text { mayorías). }\end{array}$ & $\begin{array}{l}\text { - Los términos llevan asociados ideas y conceptos } \\
\text { que representan los valores culturalmente } \\
\text { aceptados, de modo que para cambiar ideas } \\
\text { es preciso cambiar las palabras y suprimir } \\
\text { nomenclaturas negativas. } \\
\text { - Promueve una nueva visión social de las personas } \\
\text { con diversidad funcional. } \\
\text { - La diferencia es inherente al ser humano. } \\
\text { Las personas con diversidad funcional funcionan } \\
\text { sociedad. }\end{array}$ & $\begin{array}{l}\text { - Persona con } \\
\text { diversidad } \\
\text { funcional } \\
\text { - Mujeres y hombres } \\
\text { con diversidad } \\
\text { funcional. }\end{array}$ \\
\hline
\end{tabular}

Nota: la presentación de los modelos se realizó de manera cronológica, pero todos coexisten en la actualidad.

Fuente: elaboración propia. Se tomó como referente a los siguientes autores: Arce, 2015; Barnes, 2007, 2010; Guzmán, 2012; Juárez et al., 2006; Organización Mundial de la Salud, OMS, 2001; Padilla-Muñoz, 2010; Palacios, 2008; Palacios y Bariffi (2007); Palacios y Romañach, 2006; Santofimio-Rojas, 2016; Shakespeare y Watson, 1997; Velarde, 2012; Velázquez et al., 2013. 
Las diferentes formas de explicar y entender la discapacidad nos permiten vislumbrar una constante en todos los modelos: la separación entre "la normalidad" y "la diferencia", pero su valoración alude a polos opuestos. Desde la perspectiva del modelo médico y biopsicosocial, la discapacidad es abordada como un suceso universal (similar, repetible); mientras que para el modelo social y el de la diversidad funcional, es solo una posibilidad de funcionar en el mundo. De esta manera, la valoración que se hace de la diferencia en dichos modelos fluctúa entre los extremos de la anomalía y el enriquecimiento de la humanidad.

Lo anterior resulta relevante en este estudio, ya que es fundamental visibilizar y dimensionar las implicaciones que tienen para el ejercicio profesional y para las vidas de las personas con DMD, el entendimiento que subyace a la enfermedad (Barnes, 2008; Davis, 2008; Walmsley, 2008). Es decir, las normas que dictan las formas válidas del actuar, dado que emergen de las estructuras sociales en las que todos nos encontramos inmersos, incluyendo los investigadores y las personas con DMD (Gergen, 1996; Oliver, 2008).

\section{Método}

Se realizó una revisión narrativa de la literatura sobre la DMD desde una dimensión psicosocial, con el interés de dar cuenta de: (1) qué se ha estudiado acerca de este diagnóstico, haciendo referencia a las temáticas de interés, los participantes y los contextos (países); (2) qué métodos y técnicas de investigación se han empleado, y (3) cuáles son los modelos de la discapacidad que subyacen al estudio de la DMD.

Cabe aclarar que se decidió realizar una revisión narrativa y no una revisión sistemática debido a que el interés principal de este artículo no es responder una pregunta específica de investigación sobre la DMD, ni conocer con base a la "mejor evidencia" los resultados derivados de los estudios más rigurosos (Beltrán, 2005). La pretensión es seleccionar y revisar estudios con un enfoque psicosocial, con el fin de describir o dar cuenta de un "estado del arte" de este asunto y actualizar el conocimiento.

Las búsquedas se realizaron en tres bases de datos que aluden al ámbito de las ciencias de la salud, particularmente a la disciplina médica y a la psicología: PsycINFO, PubMed y ScienceDirect. El interés de esta revisión incluye visibilizar sesgos e intereses prioritarios de quienes generan el conocimiento científico.

La búsqueda se realizó con las palabras clave "DMD", "DMD \& Well-being", "DMD \& Mental Health", "DMD \& Psychosocial" y "DMD \& Psychological Well-being" de enero de 2008 a agosto del 2018. Se consideraron pertinentes estas palabras ya que entendemos que la salud no sólo implica ausencia de afecciones o enfermedad, sino bienestar físico, emocional y mental (OMS, 2020).

Cabe señalar que la búsqueda utilizando únicamente la palabra clave DMD arrojaba un gran número de artículos en su mayoría de carácter médico, por ello los filtros para la selección de artículos en el caso PubMed y ScienceDirect se realizaron a partir de la búsqueda de esta palabra con otras palabras clave. En el caso de las búsquedas en PsycINFO, sí se utilizó esta palabra sin otros filtros por arrojar un número mucho menor de artículos, pero más enfocados a lo psicosocial. 
Para la selección de los artículos se realizó una primera revisión de los títulos que aparecieron por cada búsqueda y se descartaron del análisis los estudios relacionados únicamente con el diagnóstico, tratamiento o manejo de la enfermedad (cuidados médicos), así como los que abordaban varios tipos de distrofia. Una vez seleccionados, se identificaron y excluyeron los artículos repetidos y se realizó una revisión de sus resúmenes para clarificar cuáles abordaban los procesos psicosociales involucrados en la vida de quienes han sido diagnosticados con esta enfermedad. Tras lo anterior se confirmó o descartó su inclusión en el análisis (Figura 1).

Figura 1. Proceso de selección de los artículos

\begin{tabular}{|c|c|c|c|c|c|c|c|}
\hline $\begin{array}{l}\text { Palabras } \\
\text { clave }\end{array}$ & Base de datos & $\begin{array}{l}\mathrm{N}^{\circ} \text { total } \\
\text { de } \\
\text { artículos }\end{array}$ & $\begin{array}{c}\text { Filtro } 1 \\
N^{\circ} \text { artículos } \\
\text { seleccionados } \\
\text { por revisión } \\
\text { de títulos }\end{array}$ & $\begin{array}{c}\text { Filtro } 2 \\
\mathrm{~N}^{\circ} \text { artículos } \\
\text { seleccionados } \\
\text { por revisión de } \\
\text { resúmenes }\end{array}$ & $\begin{array}{c}\text { Filtro } 3 \\
\mathrm{~N}^{\circ} \text { artículos } \\
\text { elegidos } \\
\text { para el } \\
\text { análisis }\end{array}$ & \multirow{15}{*}{ 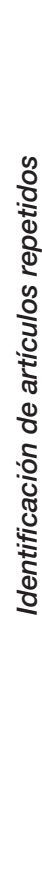 } & $\begin{array}{c}\text { Artículos } \\
\text { seleccionados }\end{array}$ \\
\hline \multirow{3}{*}{ DMD } & PSYCINFO & 336 & 35 & 29 & 14 & & \multirow{14}{*}{32} \\
\hline & PUBMED & 4.056 & - & - & - & & \\
\hline & SCIENCEDIRECT & 4.798 & - & - & - & & \\
\hline \multirow{3}{*}{$\begin{array}{c}\text { DMD \& } \\
\text { Pyschological } \\
\text { Well-being }\end{array}$} & PSYCINFO & 0 & - & - & - & & \\
\hline & PUBMED & 5 & 2 & 1 & 1 & & \\
\hline & SCIENCEDIRECT & 146 & 16 & 14 & 12 & & \\
\hline \multirow{3}{*}{$\begin{array}{c}\text { DMD \& } \\
\text { Well-being }\end{array}$} & PSYCINFO & 0 & - & - & - & & \\
\hline & PUBMED & 9 & 1 & 1 & 1 & & \\
\hline & SCIENCEDIRECT & 3 & 0 & 0 & 0 & & \\
\hline \multirow{3}{*}{$\begin{array}{c}\text { DMD \& } \\
\text { Mental health }\end{array}$} & PSYCINFO & 0 & - & - & - & & \\
\hline & PUBMED & 41 & 7 & 6 & 6 & & \\
\hline & SCIENCEDIRECT & 161 & 13 & 9 & 8 & & \\
\hline \multirow{2}{*}{$\begin{array}{c}\text { DMD \& } \\
\text { Pyschological }\end{array}$} & PUBMED & 31 & 19 & 10 & 10 & & \\
\hline & SCIENCEDIRECT & 76 & 16 & 8 & 6 & & \\
\hline
\end{tabular}

Fuente: elaboración propia.

\section{Resultados}

Se seleccionaron 32 artículos y se identificaron los siguientes aspectos (Tabla 2): el tema de interés, los participantes, el país donde se realizó la investigación, la metodología y métodos utilizados, las disciplinas y los profesionales de salud involucrados y, finalmente, los modelos de la discapacidad que subyacen al estudio de la DMD. 
Las investigaciones que se han interesado en los aspectos psicosociales de la DMD han sido desarrolladas principalmente en el continente europeo (Reino Unido, Italia, Países Bajos y Suiza) y el en el continente americano (Estados Unidos, Brasil y Canadá) siendo el Reino Unido el país con mayor número de publicaciones. Se identificaron pocos estudios en otras latitudes tales como la India, Taiwan, Turquía y Australia.

Los estudios suelen ser de dos tipos: (1) los enfocados en los familiares (padres, madres, hermanos y cuidadores de niños y jóvenes con DMD) y (2) los interesados en conocer aspectos de la vida de los niños, jóvenes y adultos que han sido diagnosticados con DMD. Es importante señalar que, si bien en el segundo tipo de estudios lo primordial es dar cuenta de la perspectiva de las personas que son diagnosticadas con la enfermedad, una gran parte de ellos integra a la par la perspectiva de los padres.

\subsection{Estudios con familiares y cuidadores de personas con DMD}

Los temas de interés están relacionados: (a) con el desgaste de los cuidadores, enfatizándose el papel de las madres como las principales cuidadoras y en consecuencia como las principales afectadas en su calidad de vida, aunque algunos estudios también han considerado el desgaste de los hermanos de niños y adolescentes con DMD (Magliano et al., 2014); (b) con explorar la experiencia de mujeres portadoras, y (c) con la preparación de los padres en el proceso de transición a la adultez de sus hijos, ya que esto les permite planear y favorecer el desarrollo integral de los adolescentes, aumentando las aspiraciones en su vida y visualizándolos a futuro como personas adultas cuyas necesidades irán más allá de la escuela y los tratamientos (Hoskin, 2017).

El desgaste físico y emocional de los familiares se ha asociado con variables tales como: la afectación de la calidad del sueño (Nozoe et al., 2016; Read et al., 2010); las preocupaciones de los padres a lo largo de la vida de un hijo con DMD (Peay, et al., 2015); la afectación de la calidad de vida (de Moura et al., 2015) y el nivel de ansiedad de las madres (Ozyurt et al., 2015); así como con la identificación de mediadores psicosociales (estresores y recursos familiares) que pueden impactar en el funcionamiento familiar (Chen, 2008) y en el caso de Thomas et al. (2014) con la identificación de necesidades psicosociales que pueden favorecer el bienestar de los cuidadores.

La experiencia de las portadoras del gen de la DMD se ha estudiado para conocer el proceso que implica para las madres comunicar a sus hijas que pueden ser posibles portadoras (Hayes et al., 2016), así como el impacto que tiene en la vida de las mujeres esta noticia, particularmente el hecho de someterse a la prueba para confirmar si se tiene el riesgo de heredar la enfermedad y el papel que juega la edad en dicha notificación (Fraser et al., 2018).

\subsection{Estudios con niños, adolescentes y adultos diagnosticados con DMD}

Los estudios en los que participan personas con DMD pueden dividirse en cinco rubros temáticos:

a. Problemas del neurodesarrollo y afectaciones cognitivas y conductuales tanto en niños como en adolescentes diagnosticados con DMD (Colombo et al., 2017; Donders y Taneja, 2009; Hendriksen et 
al., 2018; Perumal et al., 2015), ya que la DMD ha sido vinculada con problemas de lectoescritura y un pobre desempeño escolar (Astrea et al., 2015).

b. La afectación de la calidad de vida de los niños, jóvenes y adultos con DMD, enfatizando aspectos físicos (fatiga y dolor) y psicológicos (ansiedad y depresión) (Landfeldt et al., 2016; Lim, 2014; Pangalila et al., 2015a, 2015b; Simon et al., 2011; Travlos et al., 2017; Uzark et al., 2012; Wei et al., 2016).

c. La resiliencia en niños y adolescentes para identificar aspectos que favorecen un mejor ajuste a su condición de vida (Fee y Hinton, 2011).

d. La transición a la adultez, dimensionando que la DMD no es solamente una enfermedad de la infancia. Se ha buscado promover la identificación de aspectos que favorecen la transición hacia esta etapa de vida, tales como las dificultades que enfrentan en el paso de un hospital pediátrico a uno para adultos (Lindsay et al., 2017), la relevancia de visualizar la llegada a la adultez y la posibilidad de preparase para ello, a través de identificar futuras necesidades y cuidados (Kohler et al., 2009), desarrollar habilidades de lectoescritura (Hoskin y Fawcett, 2014) que aumenten las posibilidades de lograr sus metas tanto académicas como laborales (Abbot et al., 2012) y planear el fin de la vida (Abbot et al.,2017).

e. La experiencia de vivir con DMD explorando el impacto que tiene para ellos esta condición de vida, desde su propia perspectiva y dando cuenta de diferentes ámbitos implicados en la vida de una persona con DMD: el escolar, el laboral, el social y el familiar, incluyendo el impacto emocional de las intervenciones médicas y quirúrgicas en el ámbito hospitalario (Abbot y Carpenter, 2015).

Los modelos de la discapacidad que subyacen al estudio de la DMD en estas investigaciones son principalmente el biopsicosocial seguido por el social, aunque en menor medida. Se sigue aludiendo a supuestos del modelo médico en los que predomina un entendimiento y abordaje de la DMD desde la mirada de los profesionales de salud, centrada en el diagnóstico y tratamiento, particularmente en los problemas cognitivos y conductuales.

Las áreas disciplinares que se han interesado en el abordaje psicosocial de la DMD son: la medicina, la pediatría, la neurología, la genética, la cardiología, la psiquiatría, la enfermería, la psicología, la fisioterapia y la terapia ocupacional. En la mayoría de los casos colaboran diferentes médicos especialistas, en menos proporción se colabora entre áreas disciplinares y solamente se consideraron a familias y pacientes con DMD como parte del equipo de investigación en dos estudios (Hoskin, 2017; Hoskin y Fawcet, 2014) de los 32 revisados.

La revisión de cada uno de los artículos nos permite dimensionar matices de la imperiosa presencia del modelo médico en el abordaje de la DMD. Y si bien no es sorpresivo este dato, dado que el tratamiento suele estar a cargo de diversos especialistas de la medicina (Birnkrant et al., 2018b; Edwards y Philips, 2016) cabe visibilizar su predominancia, misma que dicta el tipo de estudios a realizar y los intereses de los profesionales de la salud (Gerber, 2008), ya que aun cuando los estudios consideraron necesario estudiar tanto los aspectos biológicos como los sociales, el conocimiento parece estar dirigido en mayor medida a los expertos en salud y no propiamente hacia las personas expertas en la cotidianidad, es decir, a las personas que viven con esta enfermedad en el día a día (Oliver, 2008; Walmsey, 2008).

En este sentido, es importante señalar el gran interés de explorar la perspectiva de los cuidadores en cuanto a su nivel de satisfacción y calidad de vida, pero además en el hecho de contrastarla con la perspectiva de 
sus hijos, evidenciando así la necesidad de dar cuenta de la singularidad de la experiencia ante el hecho de vivir con una condición de vida crónica, progresiva, discapacitante y letal, ya que los hijos suelen tener una valoración más positiva de su vida en comparación con la de los padres (Fee y Hinton, 2011; Landfeldt et al., 2016; Ozyurt et al., 2015; Simon et al., 2010), revelando que existen diversas formas de afrontar la enfermedad y vivir con ella, pues la experiencia se ve permeada también por factores contextuales (Gergen, 1996; Chen, 2008). Sin embargo, las metodologías implementadas parecen aludir a la generalización de la experiencia de vivir con DMD y tratar de medir de manera objetiva cada una de las variables o factores asociados a la vida de las personas con este diagnóstico, de manera que únicamente en seis investigaciones la estrategia metodológica fue cualitativa.

Los contextos sociales, culturales, económicos y políticos también juegan un papel fundamental en la generación del conocimiento (Gergen, 1996), ya que mientras en los países de primer mundo (Reino Unido y Estados Unidos) es posible dar cuenta de grandes investigaciones y colaboraciones derivadas de los recursos económicos destinados a la investigación y a la cobertura sanitaria, en los países menos desarrollados estos estudios llegan a representar un referente en el abordaje de la DMD, tal es el caso de México que hasta el momento no cuenta con cifras oficiales de la prevalencia e incidencia de la enfermedad (VázquezCárdenas et al., 2013), y por ello alude al uso de las cifras internacionales. Y si bien se han desarrollado investigaciones en este país, el tipo de estudio y las temáticas de interés suelen estar acotadas al ámbito médico (Coral-Vázquez et al., 2010; Cruz et al., 2012; de la Peña et al., 2017; Luna-Angulo et al., 2016) y aunque existe un ínfimo número de estudios que abordan aspectos psicosociales (Castillo, 2013; de Alba et al., 2015; Fokkema et al., 2013) el modelo que delinea las investigaciones también es el médico. Es importante señalar que estos estudios no se incluyeron como parte del análisis ya que las bases de datos consultadas no arrojaron dichos estudios.

Y finamente, los contextos también permiten dar cuenta del rol que juegan las personas con discapacidad en la sociedad, ya que en algunas investigaciones se vuelve vital su voz, no sólo para la capacitación y especialización de los profesionales, sino por las implicaciones sociales que conlleva el aumento de la esperanza de vida de las personas con DMD, particularmente en aspectos relacionados con la autonomía y la participación en la planeación del futuro en diversos ámbitos de la vida (Abbot, et al., 2017; Abbot y Carpenter, 2015; Hoskin, 2017; Hoskin y Fawcett, 2014; Kohler et al., 2009; Lindsay et al., 2017), es decir, aspectos relacionados con un modelo social de la discapacidad. 
Tabla 2. Investigaciones psicosociales de la distrofia muscular de Duchenne

\begin{tabular}{|c|c|c|c|c|c|c|c|}
\hline Tema & Subtema & $\begin{array}{l}\text { Autores } \\
\text { (año) }\end{array}$ & País & Participantes & $\begin{array}{l}\text { Metodología de } \\
\text { investigación }\end{array}$ & $\begin{array}{l}\text { Área disciplinar } \\
\text { que realizó el } \\
\text { estudio }\end{array}$ & $\begin{array}{c}\text { Modelo de } \\
\text { discapacidad }\end{array}$ \\
\hline & $\begin{array}{l}\text { 1. Calidad del } \\
\text { sueño de madres } \\
\text { cuidadoras }\end{array}$ & $\begin{array}{l}\text { Nozoe et al. } \\
(2016)\end{array}$ & Brasil & $\begin{array}{l}\text { Madres cuidadoras } \\
\text { de hijos con DMD }\end{array}$ & $\begin{array}{l}\text { Cuantitativo } \\
\text { (cuestionarios; } \\
\text { análisis } \\
\text { estadístico) }\end{array}$ & - Psicobiología & Biopsicosocial \\
\hline \multirow{7}{*}{ 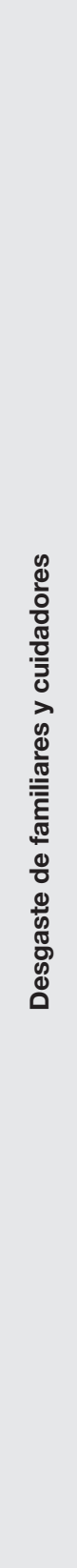 } & $\begin{array}{l}\text { 2. Dependencia } \\
\text { funcional de } \\
\text { pacientes con } \\
\text { DMD y afectación } \\
\text { de la calidad } \\
\text { de vida los } \\
\text { cuidadores } \\
\end{array}$ & $\begin{array}{l}\text { de Moura et } \\
\text { al. (2015) }\end{array}$ & Brasil & $\begin{array}{l}\text { Madres, padres } \\
\text { y hermanos de } \\
\text { pacientes con } \\
\text { DMD }\end{array}$ & $\begin{array}{l}\text { Cuantitativo } \\
\text { (cuestionarios } \\
\text { y entrevistas; } \\
\text { análisis } \\
\text { estadístico) }\end{array}$ & $\begin{array}{l}\text { - Medicina } \\
\text { - Fisioterapia } \\
\text { - Neurología }\end{array}$ & Biopsicosocial \\
\hline & $\begin{array}{l}\text { 3. Priorización } \\
\text { de las } \\
\text { preocupaciones } \\
\text { de los cuidadores }\end{array}$ & $\begin{array}{l}\text { Peay et al. } \\
(2015)\end{array}$ & $\begin{array}{l}\text { Estados } \\
\text { Unidos }\end{array}$ & $\begin{array}{l}\text { Padres de niños } \\
\text { con DMD }\end{array}$ & $\begin{array}{l}\text { Cuantitativa } \\
\text { (encuesta; análisis } \\
\text { estadístico) }\end{array}$ & - Medicina & Biopsicosocial \\
\hline & $\begin{array}{l}\text { 4. Nivel de ansiedad } \\
\text { de las madres } \\
\text { asociada a la } \\
\text { calidad del sueño } \\
\text { de sus hijos }\end{array}$ & $\begin{array}{l}\text { Ozyurt et al. } \\
(2015)\end{array}$ & Turquía & $\begin{array}{l}\text { Niños con DMD y } \\
\text { madres }\end{array}$ & $\begin{array}{l}\text { Cuantitativo } \\
\text { (inventarios y } \\
\text { cuestionarios) }\end{array}$ & $\begin{array}{l}\text { - Psiquiatría } \\
\text { - Pediatría } \\
\text { - Neurología }\end{array}$ & Biopsicosocial \\
\hline & $\begin{array}{l}\text { 5. Retos } \\
\text { psicosociales de } \\
\text { los cuidadores }\end{array}$ & $\begin{array}{l}\text { Thomas et } \\
\text { al. (2014) }\end{array}$ & India & $\begin{array}{l}\text { Cuidadores de } \\
\text { niños con DMD }\end{array}$ & $\begin{array}{l}\text { Cuantitativa } \\
\text { (entrevista } \\
\text { estructurada, } \\
\text { escalas e } \\
\text { inventarios; } \\
\text { análisis } \\
\text { estadístico) }\end{array}$ & $\begin{array}{l}\text { - Medicina } \\
\text { - Trabajo social } \\
\text { - Psicología }\end{array}$ & Biopsicosocial \\
\hline & $\begin{array}{l}\text { 6. Dificultades } \\
\text { psicológicas } \\
\text { y prácticas } \\
\text { de padres y } \\
\text { hermanos de } \\
\text { niños con DMD }\end{array}$ & $\begin{array}{l}\text { Magliano et } \\
\text { al. (2014) }\end{array}$ & Italia & $\begin{array}{l}\text { Familiares de } \\
\text { pacientes con } \\
\text { DMD }\end{array}$ & $\begin{array}{l}\text { Cuantitativa } \\
\text { (cuestionarios; } \\
\text { análisis } \\
\text { estadístico) }\end{array}$ & $\begin{array}{ll}\text { - } & \text { Psicología } \\
\text { - } & \text { Nedicina } \\
& \text { rehabilitación } \\
\text { - Neurociencias } \\
\text { - Neurología } \\
\text { - pediátrica } \\
\text { - Cardiología } \\
\text { - Genética }\end{array}$ & Biopsicosocial \\
\hline & $\begin{array}{l}\text { 7. Calidad del sueño } \\
\text { de los cuidadores } \\
\text { y afectaciones a } \\
\text { la salud mental }\end{array}$ & $\begin{array}{l}\text { Read et al. } \\
(2010)\end{array}$ & $\begin{array}{l}\text { Reino } \\
\text { Unido }\end{array}$ & $\begin{array}{l}\text { Cuidadores de } \\
\text { pacientes con } \\
\text { enfermedades } \\
\text { neuromusculares } \\
\text { y ventilación } \\
\text { nocturna. }\end{array}$ & $\begin{array}{l}\text { Mixto } \\
\text { (cuestionarios, } \\
\text { escalas y } \\
\text { entrevista } \\
\text { semiestructurada; } \\
\text { análisis estadístico } \\
\text { y codificación de } \\
\text { la entrevista) }\end{array}$ & - Neurología & Biopsicosocial \\
\hline & $\begin{array}{l}\text { 8. Mediadores } \\
\text { psicosociales que } \\
\text { afectan la salud } \\
\text { parental y la de la } \\
\text { familia }\end{array}$ & Chen (2008) & Taiwan & $\begin{array}{l}\text { Padres de hijos } \\
\text { con DMD }\end{array}$ & $\begin{array}{l}\text { Cuantitativo } \\
\text { (instrumentos } \\
\text { para medir los } \\
\text { mediadores } \\
\text { psicosociales; } \\
\text { análisis } \\
\text { estadístico) }\end{array}$ & - Medicina & Biopsicosocial \\
\hline
\end{tabular}




\begin{tabular}{|c|c|c|c|c|c|c|c|}
\hline Tema & Subtema & $\begin{array}{l}\text { Autores } \\
\text { (año) }\end{array}$ & País & Participantes & $\begin{array}{l}\text { Metodología de } \\
\text { investigación }\end{array}$ & $\begin{array}{l}\text { Área disciplinar } \\
\text { que realizó el } \\
\text { estudio }\end{array}$ & $\begin{array}{c}\text { Modelo de } \\
\text { discapacidad }\end{array}$ \\
\hline \multirow{2}{*}{$\begin{array}{l}\frac{0}{\pi} \\
\frac{0}{0} \\
\frac{0}{\pi} \\
\frac{\pi}{0} \\
\frac{0}{0} \\
\frac{d}{0} \\
\frac{0}{2} \\
\frac{D}{\Sigma}\end{array}$} & $\begin{array}{l}\text { 9. Experiencias } \\
\text { de mujeres que } \\
\text { se realizaron } \\
\text { la prueba } \\
\text { para posibles } \\
\text { portadoras } \\
\text { durante la } \\
\text { adolescencia }\end{array}$ & $\begin{array}{l}\text { Fraser et al. } \\
(2018)\end{array}$ & $\begin{array}{l}\text { Reino } \\
\text { Unido }\end{array}$ & $\begin{array}{l}\text { Mujeres que } \\
\text { se sometieron } \\
\text { a la prueba de } \\
\text { portadoras del gen } \\
\text { de DMD durante la } \\
\text { adolescencia }\end{array}$ & $\begin{array}{l}\text { Cualitativa } \\
\text { (entrevistas; } \\
\text { análisis temático) }\end{array}$ & $\begin{array}{l}\text { - Medicina } \\
\text { genómica }\end{array}$ & Biopsicosocial \\
\hline & $\begin{array}{l}\text { 10. Comunicación en } \\
\text { la familia para la } \\
\text { realización de la } \\
\text { prueba a posibles } \\
\text { portadoras }\end{array}$ & $\begin{array}{l}\text { Hayes et al. } \\
(2016)\end{array}$ & $\begin{array}{l}\text { Estados } \\
\text { Unidos }\end{array}$ & $\begin{array}{l}\text { Madres de hijos } \\
\text { con DMD }\end{array}$ & $\begin{array}{l}\text { Mixto (encuesta } \\
\text { y preguntas } \\
\text { abiertas; análisis } \\
\text { estadístico y } \\
\text { análisis temático) }\end{array}$ & $\begin{array}{l}\text { - Genética } \\
\text { - Pediatría }\end{array}$ & Biopsicosocial \\
\hline 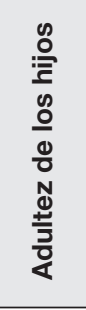 & $\begin{array}{l}\text { 11. Apoyo a los } \\
\text { padres en la } \\
\text { preparación } \\
\text { para el proceso } \\
\text { de transición } \\
\text { a la adultez } \\
\text { de los hijos } \\
\text { adolescentes con } \\
\text { DMD }\end{array}$ & $\begin{array}{l}\text { Hoskin } \\
(2017)\end{array}$ & $\begin{array}{l}\text { Reino } \\
\text { Unido }\end{array}$ & $\begin{array}{l}\text { Padres de jóvenes } \\
\text { con DMD }\end{array}$ & $\begin{array}{l}\text { Cualitativa } \\
\text { (entrevistas; } \\
\text { análisis temático) }\end{array}$ & $\begin{array}{l}\text { Grupo de } \\
\text { personas en } \\
\text { contacto con } \\
\text { personas con } \\
\text { DMD }\end{array}$ & Social \\
\hline \multirow{5}{*}{ 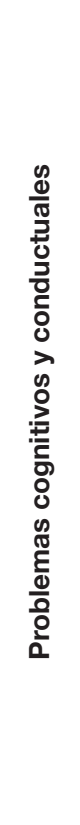 } & $\begin{array}{l}\text { 12. Comorbilidades } \\
\text { relacionadas con } \\
\text { el cerebro }\end{array}$ & $\begin{array}{l}\text { Hendriksen } \\
\text { et al. (2018) }\end{array}$ & $\begin{array}{l}\text { Países } \\
\text { Bajos }\end{array}$ & $\begin{array}{l}\text { Adolescentes con } \\
\text { DMD de Europa, } \\
\text { Estados Unidos y } \\
\text { Australia; padres }\end{array}$ & $\begin{array}{l}\text { Cuantitativa } \\
\text { (cuestionarios; } \\
\text { análisis } \\
\text { estadístico) } \\
\end{array}$ & $\begin{array}{ll}\text { - } & \text { Neurología } \\
\text { - Neurocirugía } \\
\text { - Neurociencia } \\
\text { - Pediátrica } \\
\end{array}$ & Médico \\
\hline & $\begin{array}{l}\text { 13. Evaluación de } \\
\text { la salud mental: } \\
\text { emocional, } \\
\text { conductual } \\
\text { y perfil del } \\
\text { neurodesarrollo }\end{array}$ & $\begin{array}{l}\text { Colombo et } \\
\text { al. (2017) }\end{array}$ & Italia & $\begin{array}{l}\text { Niños y } \\
\text { adolescentes con } \\
\text { DMD }\end{array}$ & $\begin{array}{l}\text { Cuantitativa } \\
\text { (escalas, } \\
\text { cuestionarios y } \\
\text { entrevista clínica } \\
\text { estructurada) }\end{array}$ & $\begin{array}{l}\text { - Psicología } \\
\text { - Neurología } \\
\text { - Neuro- } \\
\text { rehabilitación }\end{array}$ & Médico \\
\hline & $\begin{array}{l}\text { 14. Habilidades de } \\
\text { lectoescritura en } \\
\text { niños con DMD }\end{array}$ & $\begin{array}{l}\text { Astrea et al. } \\
(2015)\end{array}$ & Italia & $\begin{array}{l}\text { Niños con DMD } \\
\text { Niños con } \\
\text { desarrollo típico } \\
\text { Niños con dislexia }\end{array}$ & $\begin{array}{l}\text { Cuantitativa } \\
\text { (batería de } \\
\text { instrumentos } \\
\text { psicométricos; } \\
\text { análisis } \\
\text { estadístico) }\end{array}$ & $\begin{array}{l}\text { - Neurología } \\
\text { - Cardiología } \\
\text { - Genética }\end{array}$ & Médico \\
\hline & $\begin{array}{l}\text { 15. Perfil } \\
\text { neuropsicológico } \\
\text { de jóvenes con } \\
\text { DMD }\end{array}$ & $\begin{array}{l}\text { Perumal et } \\
\text { al. (2015) }\end{array}$ & India & Niños con DMD & $\begin{array}{l}\text { Cuantitativa } \\
\text { (batería de } \\
\text { instrumentos } \\
\text { psicométricos) }\end{array}$ & $\begin{array}{l}\text { - Psicología } \\
\text { - Neurología } \\
\text { - Neuropsicología }\end{array}$ & Biopsicosocial \\
\hline & $\begin{array}{l}\text { 16. Características } \\
\text { del } \\
\text { neurodesarrollo }\end{array}$ & $\begin{array}{l}\text { Donders } \\
\text { y Taneja } \\
(2009)\end{array}$ & $\begin{array}{l}\text { Estados } \\
\text { Unidos }\end{array}$ & $\begin{array}{l}\text { Niños y } \\
\text { adolescentes con } \\
\text { DMD }\end{array}$ & $\begin{array}{l}\text { Cuantitativa } \\
\text { (escalas e } \\
\text { inventarios) }\end{array}$ & - Psicología & Médico \\
\hline
\end{tabular}




\begin{tabular}{|c|c|c|c|c|c|c|c|}
\hline Tema & Subtema & $\begin{array}{l}\text { Autores } \\
\text { (año) }\end{array}$ & País & Participantes & $\begin{array}{l}\text { Metodología de } \\
\text { investigación }\end{array}$ & $\begin{array}{l}\text { Área disciplinar } \\
\text { que realizó el } \\
\text { estudio }\end{array}$ & $\begin{array}{l}\text { Modelo de } \\
\text { discapacidad }\end{array}$ \\
\hline \multirow{9}{*}{$\begin{array}{l}\frac{\pi}{0} \\
\frac{0}{3} \\
\frac{0}{0} \\
\frac{\pi}{0} \\
\frac{\pi}{0} \\
\frac{0}{0}\end{array}$} & $\begin{array}{l}\text { 17. Calidad de vida y } \\
\text { bienestar social } \\
\text { de personas con } \\
\text { enfermedades } \\
\text { neuromusculares } \\
\text { que usan silla de } \\
\text { ruedas }\end{array}$ & $\begin{array}{l}\text { Travlos et } \\
\text { al. (2017) }\end{array}$ & Australia & Jóvenes con DMD & $\begin{array}{l}\text { Revisión } \\
\text { sistemática }\end{array}$ & $\begin{array}{l}\text { - Psicología } \\
\text { - Neurología } \\
\text { - Neuro- } \\
\text { rehabilitación }\end{array}$ & Biopsicosocial \\
\hline & $\begin{array}{l}\text { 18. Experiencia del } \\
\text { dolor, expresión } \\
\text { y afrontamiento y } \\
\text { calidad de vida }\end{array}$ & $\begin{array}{l}\text { Hunt et al. } \\
(2016)\end{array}$ & $\begin{array}{l}\text { Reino } \\
\text { Unido }\end{array}$ & $\begin{array}{l}\text { Adolescentes y } \\
\text { adultos jóvenes } \\
\text { con DMD; padres* }\end{array}$ & $\begin{array}{l}\text { Método mixto } \\
\text { (inventarios, } \\
\text { escalas, mapas } \\
\text { del dolor y } \\
\text { entrevistas; } \\
\text { análisis estadístico } \\
\text { y análisis temático) }\end{array}$ & - Psicología & Biopsicosocial \\
\hline & $\begin{array}{l}\text { 19. Calidad de vida } \\
\text { relacionada con } \\
\text { la salud }\end{array}$ & $\begin{array}{l}\text { Ladnfeldt et } \\
\text { al. (2016) }\end{array}$ & $\begin{array}{l}\text { Reino } \\
\text { Unido }\end{array}$ & $\begin{array}{l}\text { Pacientes con } \\
\text { DMD y sus } \\
\text { cuidadores* de } \\
\text { Italia, Alemania, } \\
\text { Reino Unido y } \\
\text { Estados Unidos. }\end{array}$ & $\begin{array}{l}\text { Cuantitativa } \\
\text { (cuestionario e } \\
\text { inventario por } \\
\text { e-mail; análisis } \\
\text { estadístico) }\end{array}$ & $\begin{array}{l}\text { - } \text { Medicina } \\
\text { ambiental } \\
\text { - Genética } \\
\text { - Neurología } \\
\text { pediátrica }\end{array}$ & Biopsicosocial \\
\hline & $\begin{array}{l}\text { 20. Factores } \\
\text { asociados con la } \\
\text { salud relacionada } \\
\text { con la calidad de } \\
\text { vida }\end{array}$ & $\begin{array}{l}\text { Wei et al. } \\
(2016)\end{array}$ & Canadá & $\begin{array}{l}\text { Niños, } \\
\text { adolescentes } \\
\text { con DMD y sus } \\
\text { familiares* }\end{array}$ & $\begin{array}{l}\text { Cuantitativa } \\
\text { (cuestionario; } \\
\text { análisis } \\
\text { estadístico) }\end{array}$ & $\begin{array}{l}\text { - Pediatría } \\
\text { - Neurología } \\
\text { - Epidemiología }\end{array}$ & Biopsicosocial \\
\hline & $\begin{array}{l}\text { 21.Prevalencia de } \\
\text { fatiga, dolor } \\
\text { y desórdenes } \\
\text { afectivos } \\
\text { asociados con la } \\
\text { calidad de vida }\end{array}$ & $\begin{array}{l}\text { Pangalila et } \\
\text { al. }(2015 a)\end{array}$ & $\begin{array}{l}\text { Países } \\
\text { Bajos }\end{array}$ & $\begin{array}{l}\text { Adultos con DMD } \\
\text { y sus cuidadores }\end{array}$ & $\begin{array}{l}\text { Cuantitativa } \\
\text { (cuestionarios; } \\
\text { análisis } \\
\text { estadístico) }\end{array}$ & $\begin{array}{l}\text { - Medicina en } \\
\text { rehabilitación y } \\
\text { terapia física } \\
\text { - Medicina social }\end{array}$ & Biopsicosocial \\
\hline & $\begin{array}{l}\text { 22. Calidad de vida e } \\
\text { implicaciones en } \\
\text { el cuidado }\end{array}$ & $\begin{array}{l}\text { Pangalila et } \\
\text { al. }(2015 b)\end{array}$ & $\begin{array}{l}\text { Países } \\
\text { Bajos }\end{array}$ & Adultos con DMD & $\begin{array}{l}\text { Cuantitativa } \\
\text { (cuestionarios; } \\
\text { análisis } \\
\text { estadístico) }\end{array}$ & $\begin{array}{l}\text { - Medicina en } \\
\text { rehabilitación y } \\
\text { terapia física } \\
\text { - Medicina social }\end{array}$ & Biopsicosocial \\
\hline & $\begin{array}{l}\text { 23. Calidad de vida } \\
\text { relacionada con } \\
\text { la salud }\end{array}$ & $\begin{array}{l}\text { Lim et al. } \\
(2014)\end{array}$ & $\begin{array}{l}\text { Estados } \\
\text { Unidos }\end{array}$ & $\begin{array}{l}\text { Niños y } \\
\text { adolescentes con } \\
\text { DMD; padres* }\end{array}$ & $\begin{array}{l}\text { Cuantitativa } \\
\text { (cuestionarios e } \\
\text { inventario; análisis } \\
\text { estadístico) }\end{array}$ & $\begin{array}{l}\text { - Terapia } \\
\text { ocupacional }\end{array}$ & Biopsicosocial \\
\hline & $\begin{array}{l}\text { 24. Calidad de vida } \\
\text { relacionada } \\
\text { con la salud en } \\
\text { adolescentes }\end{array}$ & $\begin{array}{l}\text { Uzark et al. } \\
(2012)\end{array}$ & $\begin{array}{l}\text { Estados } \\
\text { Unidos }\end{array}$ & $\begin{array}{l}\text { Niños y } \\
\text { adolescentes con } \\
\text { DMD; padres* }\end{array}$ & $\begin{array}{l}\text { Cuantitativa } \\
\text { (escalas y } \\
\text { entrevista } \\
\text { semiestructurada) }\end{array}$ & $\begin{array}{l}\text { - } \text { Cardiología } \\
\text { pediátrica } \\
\text { - Neurología } \\
\text { pediátrica }\end{array}$ & Biopsicosocial \\
\hline & $\begin{array}{l}\text { 25. Satisfacción en } \\
\text { la vida y calidad } \\
\text { de vida en } \\
\text { adolescentes }\end{array}$ & $\begin{array}{l}\text { Simon et al. } \\
(2011)\end{array}$ & Brasil & $\begin{array}{l}\text { Niños y } \\
\text { adolescentes con } \\
\text { DMD }\end{array}$ & $\begin{array}{l}\text { Cuantitativo } \\
\text { (cuestionario; } \\
\text { análisis } \\
\text { estadístico) }\end{array}$ & - Neurología & Biopsicosocial \\
\hline 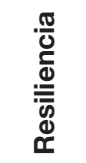 & $\begin{array}{l}\text { 26. Resiliencia en } \\
\text { niños con DMD }\end{array}$ & $\begin{array}{l}\text { Fee y } \\
\text { Hinton } \\
(2011)\end{array}$ & $\begin{array}{l}\text { Estados } \\
\text { Unidos }\end{array}$ & $\begin{array}{l}\text { Niños y } \\
\text { adolescentes con } \\
\text { DMD; cuidadores } \\
\text { primarios* }^{\star}\end{array}$ & $\begin{array}{l}\text { Cuantitativo } \\
\text { (escalas) }\end{array}$ & - Neurología & Biopsicosocial \\
\hline
\end{tabular}




\begin{tabular}{|c|c|c|c|c|c|c|c|}
\hline Tema & Subtema & $\begin{array}{l}\text { Autores } \\
\text { (año) }\end{array}$ & País & Participantes & $\begin{array}{l}\text { Metodología de } \\
\text { investigación }\end{array}$ & $\begin{array}{l}\text { Área disciplinar } \\
\text { que realizó el } \\
\text { estudio }\end{array}$ & $\begin{array}{c}\text { Modelo de } \\
\text { discapacidad }\end{array}$ \\
\hline \multirow{5}{*}{ 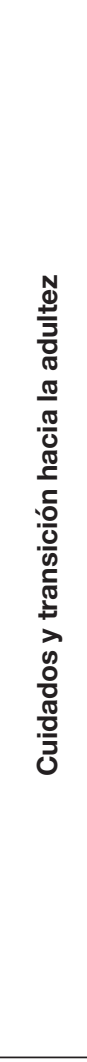 } & $\begin{array}{l}\text { 27. Barreras y } \\
\text { facilitadores } \\
\text { en la transición } \\
\text { de un hospital } \\
\text { pediátrico a un } \\
\text { hospital para } \\
\text { adultos }\end{array}$ & $\begin{array}{l}\text { Lindsay et } \\
\text { al. (2017) }\end{array}$ & Canadá & $\begin{array}{l}\text { Profesionales de } \\
\text { salud, cuidadores* } \\
\text { y jóvenes con } \\
\text { DMD }\end{array}$ & $\begin{array}{l}\text { Cualitativa } \\
\text { (entrevista en } \\
\text { profundidad } \\
\text { semiestructurada; } \\
\text { análisis temático) }\end{array}$ & $\begin{array}{l}\text { - Pediatría } \\
\text { - Rehabilitación } \\
\text { - Terapia } \\
\text { ocupacional }\end{array}$ & Biopsicosocial \\
\hline & $\begin{array}{l}\text { 28.Planeación del fin } \\
\text { de la vida }\end{array}$ & $\begin{array}{l}\text { Abbot et al. } \\
(2017)\end{array}$ & $\begin{array}{l}\text { Reino } \\
\text { Unido }\end{array}$ & Jóvenes con DMD & $\begin{array}{l}\text { Cualitativa } \\
\text { (entrevista } \\
\text { semiestructurada; } \\
\text { análisis temático) }\end{array}$ & $\begin{array}{l}\text { - Medicina } \\
\text { - Psicología }\end{array}$ & Social \\
\hline & $\begin{array}{l}\text { 29. Habilidades de } \\
\text { lectura en la } \\
\text { preparación para } \\
\text { la adultez }\end{array}$ & $\begin{array}{l}\text { Hoskin y } \\
\text { Fawcett } \\
(2014)\end{array}$ & $\begin{array}{l}\text { Reino } \\
\text { Unido }\end{array}$ & Niños con DMD & $\begin{array}{l}\text { Cuantitativa } \\
\text { (batería de } \\
\text { instrumentos } \\
\text { para evaluación } \\
\text { y un programa } \\
\text { de intervención; } \\
\text { análisis } \\
\text { estadístico) } \\
\end{array}$ & $\begin{array}{l}\text { - Grupo de } \\
\text { personas en } \\
\text { contacto con } \\
\text { personas con } \\
\text { DMD }\end{array}$ & Social \\
\hline & $\begin{array}{l}\text { 30. Transición hacia } \\
\text { la adultez }\end{array}$ & $\begin{array}{l}\text { Abbot et al. } \\
(2012)\end{array}$ & $\begin{array}{l}\text { Reino } \\
\text { Unido }\end{array}$ & $\begin{array}{l}\text { Jóvenes con } \\
\text { DMD, padres* y } \\
\text { hermanos }\end{array}$ & $\begin{array}{l}\text { Cualitativa } \\
\text { (entrevistas) }\end{array}$ & - Medicina & Social \\
\hline & $\begin{array}{l}\text { 31.Perfil de } \\
\text { sobrevivencia } \\
\text { y discapacidad } \\
\text { que permiten } \\
\text { la planeación } \\
\text { de cuidados y } \\
\text { necesidades a } \\
\text { largo plazo }\end{array}$ & $\begin{array}{l}\text { Kohler et al. } \\
(2009)\end{array}$ & Suiza & $\begin{array}{l}\text { Niños, } \\
\text { adolescentes y } \\
\text { adultos con DMD }\end{array}$ & $\begin{array}{l}\text { Cuantitativa } \\
\text { (examen físico } \\
\text { e instrumento; } \\
\text { análisis } \\
\text { estadístico) }\end{array}$ & $\begin{array}{l}\text { - } \text { Medicina } \\
\text { - } \text { Fulmonar } \\
\text { - Fisiología }\end{array}$ & Biopsicosocial \\
\hline 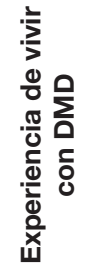 & $\begin{array}{l}\text { 32. Impacto de vivir } \\
\text { con DMD }\end{array}$ & $\begin{array}{l}\text { Abbot y } \\
\text { Carpenter } \\
(2015)\end{array}$ & $\begin{array}{l}\text { Reino } \\
\text { Unido }\end{array}$ & $\begin{array}{l}\text { Niños y jóvenes } \\
\text { con DMD; en } \\
\text { algunos casos } \\
\text { los padres }{ }^{\star} \text { y } \\
\text { hermanos }\end{array}$ & $\begin{array}{l}\text { Cualitativa } \\
\text { (entrevista } \\
\text { semiestructurada; } \\
\text { análisis de } \\
\text { contenido } \\
\text { temático) }\end{array}$ & - Trabajo social & Social \\
\hline
\end{tabular}

Nota 1: el área sombreada indica que las investigaciones abordan temas enfocados en los cuidadores; el área no sombreada indica que son investigaciones enfocadas en niños, adolescentes y adultos jóvenes con DMD.

Nota 2: el * indica que en el estudio también participaron los padres o algún miembro de la familia, pero el foco de interés eran los niños, jóvenes o adultos que viven con DMD.

Fuente: elaboración propia. Los estudios se presentan por bloques temáticos y del más actual al más antiguo. 


\section{Conclusiones}

La revisión narrativa realizada no solo permitió conocer de qué manera se ha estudiado la DMD desde una perspectiva psicosocial, sino que además permite visibilizar que es necesario ampliar el abordaje de esta enfermedad a través de metodologías y métodos de investigación que promuevan la colaboración de voces y saberes disciplinares, pero sobre todo que den lugar a la voz de las personas con DMD, pues son escasos los que aluden a este tipo de abordaje, pero muy necesarios para comprender que la vida de los niños, adolescentes y jóvenes con DMD tiene un sentido singular que requiere ser considerado.

Cabe señalar que si bien en el papel se plantean los grandes avances en cuanto a la manera de abordar la DMD, modelos como el social o el de diversidad funcional siguen siendo poco aplicados en los estudios, por lo que es necesario ir desarrollando más investigación desde estas perspectivas, para permear la práctica clínica pero, sobre todo, que las opiniones y puntos de vista de los niños, jóvenes y adultos que viven con esta enfermedad tengan incidencia en la detección, el tratamiento y en la implementación de políticas públicas que permitan el goce y ejercicio de los derechos de las personas con enfermedades tan complejas como la DMD.

Finalmente, reconocemos que el análisis que aquí se presenta no es exhaustivo dado que únicamente se realizó la búsqueda en tres bases de datos y en una temporalidad delimitada (enero del 2008 a agosto del 2018), pero se cumplió el objetivo planteado, es decir, brindar un panorama del abordaje psicosocial de la DMD, así como visibilizar los vacíos y sesgos para su abordaje, ya que se hizo evidente el predominio de un modelo médico. 


\section{Referencias bibliográficas}

Abbot, D. y Carpenter, J. (2015). “'The things that are Inside of you are horrible': children and young men with Duchenne muscular dystrophy talk about the impact of living with a long-term condition". Child Care in Practice, 21(1), pp. 67-77.

Abbot, D. et al. (2012). "Transition to adulthood for young men with Duchenne muscular dystrophy: Research from the UK”. Neuromuscular Disorders, 22, pp. 445-446.

Abbot, D. et al. (2017). "Men with Duchenne muscular dystrophy and end of life planning". Neuromuscular Disorder, 27 , pp. 38-44.

Alba, M. de et al. (2015). "Riesgo Suicida y síntomas depresivos en padres de hijos con enfermedades neuromusculares". Acta de Investigación Psicológica, 5(1), pp. 1872-1880.

Arce, J. (2015). "Una aproximación a la relación entre los modelos teóricos de discapacidad y las políticas públicas". Revista de Ciencias Humanas, 12, pp. 109-122.

Astrea, G. et al. (2015). "Reading impairment in Duchenne muscular dystrophy: A pilot study to investigate similarities and differences with developmental dyslexia". Research in Developmental Disabilities, 45-46, pp. $168-177$.

Barnes, C. (2007). "Disability activism and the struggle for change: disability, policy and politics in the UK". Education, Citizenship and Social Justice, 2(3), pp. 203-221.

Barnes, C. (2008). "La diferencia producida en una década: Reflexiones sobre la investigación "emancipadora" en investigación”. En L. Barton (comp.), Superar las barreras de la discapacidad. Madrid: Morata.

Barnes, C. (2010). "Discapacidad, política y pobreza en el contexto del 'Mundo Mayoritario'”. Política y Sociedad, 47(1), pp. 11-25.

Beltrán, O. A. (2005). "Revisiones sistemáticas de la literatura". Revista colombiana de gastroenterología, 20(1), pp. 60-69.

Birnkrant, D. et al. (2018a). "Diagnosis and management of Duchenne muscular dystrophy, part1: diagnosis, and neuromuscular, rehabilitation, endocrine, and gastrointestinal and nutritional management". Lancet Neurology, pp. 1-17.

Birnkrant, D. et al. (2018b). "Diagnosis and management of Duchenne muscular dystrophy, part 3: primary care, emergency management, psychosocial care, and transitions of care across the lifespan". Lancet Neurology, pp. 1-11.

Birnkrant, D. et al. (2018c). "Diagnosis and management of Duchenne muscular dystrophy, part 2. Respiratory, cardiac, bone health, and orthopedic management". Lancet Neurology, pp. 1-15.

Bushby, K. et al. (2010a): "Diagnosis and management of Duchenne muscular dystrophy, part 1: diagnosis, and pharmacological and psychosocial management". Lancent Neurology, 9: 77-93.

Bushby, K. et al. (2010b). "Diagnosis and management of Duchenne muscular dystrophy, part 2: implementation of multidisciplinary care. Lancent Neurology, 9, pp. 177-189.

Cammarata-Scalisi, F. et al. (2008). "Distrofia muscular de Duchenne, presentación clínica". Revista Chilena de Pediatría, 79(5), pp. 495-501. 
Castiglioni, C. et al. (2018). "Enfermedades neuromusculares. Epidemiología y Políticas de Salud en Chile". Revista Médica Clínica Las Condes, 29(6), pp. 594-598.

Castillo, G. (2013). "Estudio de caso: análisis narrativo con base en el relato autobiográfico de un paciente con distrofia muscular". Investigación y Ciencia de la Universidad de Aguascalientes, 58, pp. 55-60.

Chaustre D. y Chona, W. (2011). "Distrofia muscular de Duchenne. Perspectivas desde la rehabilitación”. Revista Med, 19(1), pp. 45-55.

Chen, J. (2008). "Mediators affecting family function in families of children with Duchenne muscular dystrophy". Kaohsiung J Med Sci, 24(10), pp. 514-522.

Colombo, P. et al. (2017). "Assessing mental health in boys with Duchenne muscular dystrophy: emotional, behavioural and neurodevelopmental profile in an Italian clinical sample". European Journal of Paediatric Neurology, 21(4), pp. 639-647.

Coral-Vázquez. R. et al. (2010). "Distrofias musculares en México: un enfoque clínico, bioquímico y molecular". Revista de Especialidades Médico-Quirúrgicas, 15(3), pp. 152-160.

Cruz, l. et al. (2012). "Descripción de las características de la capacidad funcional en niños con distrofia muscular de Duchenne". Boletín de la Sociedad de Pediatría de Asturias, Cantabria, Castilla y León, 52, pp. 23-28.

Daack-Hirsch, S. et al. (2013). "Parental perspectives on the diagnostic process for Duchenne and Becker muscular dystrophy". American Journal of Medical Genetics, Part A 161A, pp. 687-695.

Davis, M. (2008). "Investigaciones y textos etnográficos en el ámbito de los estudios sobre discapacidad". En L. Barton (comp.), Superar las barreras de la discapacidad. Madrid: Morata.

Donders, J. y Taneja, C. (2009). "Neurobehavioral characteristics of children with Duchenne muscular dystrophy". Child Neurology, 15, pp. 295-304.

Eagle, M. et al. (2007). "Managing Duchenne muscular dystrophy - The additive effect of spinal surgery and home nocturnal ventilation in improving survival”. Neuromuscular Disorders, 17(6), pp. 470-475.

Earle, N. y Bevilacqua, J. (2018). “Distrofias musculares en el paciente adulto”. Revista Médica Clínica Las Condes, 29(6), pp. 599-610.

Edwards, L. y Philips, M. (2016). "Neuromuscular conditions for physicians-what you need know". Clinical Medicine, 16(3), pp. 259-261.

Fee, R. y Hinton, V. (2011). "Resilience in children diagnosed with a chronic neuromuscular disorder". J Dev Behav Pediatr, 32, pp. 644-650.

Flanigan, K. (2014). “Duchenne and Becker muscular dystrophies”. Neurologic Clinic, 32, pp. 671-688.

Fokkema, J. et al. (2013). "Impacto de las organizaciones de padres en la investigación de la distrofia muscular de Duchenne: el activismo materno como motor de cambio". Investigación en Discapacidad, 2(3), pp. 135-140.

Fraser, H. et al. (2018). "Experiences of women who have had carrier testing for Duchenne muscular dystrophy and Becker muscular dystrophy during adolescence". Journal of Genetic Counseling, 27(6), pp. 1349-1359.

Gerber, D. (2008). "Escuchar a las personas con discapacidad: El problema de la voz y la autoridad en el libro de Robert B. Edgerton The Cloack of Competence”. En L. Barton (comp.), Superar las barreras de la discapacidad. Madrid: Morata.

Gergen, K. (1996). Realidades y relaciones: aproximaciones a la construcción social. Barcelona: Paidós. 
Giliberto, F. et al. (2014). "Symptomatic female carriers of Duchenne muscular dystrophy (DMD): Genetic and clinical characterization”. Journal of Neurological Sciences, 336, pp. 36-41.

González-Herrera, P. et al. (2009). "Identificación de delecciones en el gen de la distrofina y detección de portadoras en familias con distrofia muscular de Duchenne/Becker”. Revista de Neurología, 48(2), pp. 66-70.

González-Huerta, N. C. et al. (2004). "Identificación de delecciones en el gen DMD mediante PCR múltiple en pacientes mexicanos con distrofia muscular de Duchenne/Becker". Revista del Hospital General de México, S. S., 67(4), pp. 196-202.

Gutiérrez-Rivas, E. et al. (2014). "Descripción, etiología, epidemiología, pronóstico y evolución de distrofias en la edad adulta". En C. I. Amayra et al. (eds.), Enfermedades neuromusculares: Bases para la intervención. Bilbao: Deusto. Recuperado de https://books.google.com.mx/books?hl=es\&lr=\&id=1WGJAwAAQBAJ\&oi=fnd\&pg=P A99\&dq=narrativas+y+distrofia+muscular\&ots=5_SUayrWAf\&sig=pHg8696K-H51G8iGznRGgzvWTN8\#v=one page\&q\&f$=$ false

Guzmán, F. (2012). "El binomio Discapacidad-Enfermedad. Un análisis crítico". Revista Internacional de Humanidades Médicas, 1(1), pp. 61-71.

Hayes, B. et al. (2016). "Duchenne muscular dystrophy: a survey of perspective on carriers testing and communication with the family". Journal of Genetic Counseling, 25, pp. 443-453.

Hendriksen, R. et al. (2018). "Brain-related comorbidities in boys and men with Duchenne muscular dystrophy: A descriptive study". European Journal of Paediatric Neurology, 22, pp. 488-497.

Hoskin, J. (2017). "Taking charge and letting go: exploring the ways a transition to adulthood project for teenagers with Duchenne muscular dystrophy has supported parents to prepare for the future". British Journal of Special Education, 44(2), pp. 165-190.

Hoskin, J. y Fawcett, A. (2014). "Improving the reading skills of young people with Duchenne muscular dystrophy in preparation for adulthood”. British Journal of Special Education, 41(2), pp. 172-190.

Huml, R. (ed.) (2015): Muscular Dystrophy: A Concise Guide. Suiza: Springer.

Hunt, A. et al. (2016). "Pain experience, expression and coping in boys and young men with Duchenne muscular dystrophy- A pilot study using mixed methods". European Journal of Paediatric Neurology, 20(4), pp. 630-638.

Juárez, F. et al. (2006). "Aceptación o rechazo: Perspectiva histórica sobre la discapacidad, la rehabilitación y la psicología de la rehabilitación”. Psicología y Salud, 16(2), pp. 187-197.

Kohler, M. et al. (2009). "Disability and survival in Duchenne muscular dystrophy". J Neurol Neurosurg Psychiatry, 80, pp. 320-325.

Landfeldt, E. et al. (2016). "Quantifying the burden of caregiving in Duchenne muscular dystrophy". Journal of Neurology, 263, pp. 906-915.

Lindsay, S. et al. (2017). "Enablers and barriers of men with Duchenne muscular dystrophy transitioning from an adult clinic within a pediatric hospital”. Disability and Health Journal, 10(1), pp. 73-79.

Lim, Y. (2014). "The level of agreement between child self-reports and parent proxy-reports of health-related quality of life in boys with Duchenne muscular dystrophy". Qual Life Res, 23(7), pp. 1945-1952.

Luna-Angulo, A. et al. (2016). "Diagnóstico molecular de enfermedades neuromusculares en el Instituto Nacional de Rehabilitación, situación actual y perspectivas”. Investigación en Discapacidad, 5(1), pp. 9-26. 
Magliano, L. et al. (2014). "Psychological and practical difficulties among parents and healthy siblings of children with Duchenne vs. Becker muscular dystrophy: an Italian comparative study". Acta Myologica, XXXIII, pp. 136-146.

Mah, J. et al. (2016). "A systematic review and meta-analysis on the epidemiology of the muscular dystrophies". The Canadian Journal of Neurological Sciences Inc., 43(1), pp. 163-177.

Mah, J. (2015). "Duchenne and Becker muscular dystrophies: Underlying genetic and molecular mechanism". En R. Huml (ed.), Muscular dystrophy. Suiza: Springer.

McDonald, C. et al. (2013). "The cooperative international neuromuscular research group Duchenne natural history study - a longitudinal investigation in the era of glucocorticoid therapy: Design of protocol and the methods used". Muscle \& Nerve, 48(1), pp. 32-54.

Moura, M. de et al. (2015). "Is functional dependence of Duchenne muscular dystrophy patients determinant of the quality of life and burden of their caregivers?" Arquivos de Neuropsiquiatría, 73(1), pp. 52-57.

Nozoe, K. et al. (2016). "Sleep quality of mother-caregivers of Duchenne muscular dystrophy patients". Sleep \& Breathing, 20(1), pp. 129-134.

Oliver, M. (2008). “Están cambiando las relaciones sociales de la producción investigadora?”. En L. Barton (comp.), Superar las barreras de la discapacidad. Madrid: Morata.

Organización Mundial de la Salud (OMS) (2001). Clasificación Internacional del Funcionamiento de la Discapacidad y de la Salud: CIF, versión abreviada. Recuperado de https://www.gob.mx/cms/uploads/attachment/file/2230/ CIF_OMS.pdf.

Organización Mundial de la Salud (OMS) (2020). ¿Cómo define la OMS la salud? [artículo en web]. Recuperado de https://www.who.int/es/about/who-we-are/frequently-asked-questions.

Ozyurt G. et al. (2015). "Quality of life and sleep in children diagnosed with Duchenne muscular dystrophy and their mothers' level of anxiety: a case-control study". Duşunen Adam The Journal of Psychiatry and Neurological Sciences, 28(4), pp. 362-368.

Padilla-Muñoz, A. (2010). "Discapacidad: Contexto, concepto y modelos”. International Law, Revista Colombiana de Derecho Internacional, 16, pp. 381-414.

Palacios, A. (2008). El modelo social de discapacidad: orígenes, caracterización y plasmación en la Convención Internacional sobre los Derechos de las Personas con Discapacidad. Madrid: Ediciones Cinca.

Palacios, A. y Bariffi, F. (2007). La discapacidad como una cuestión de derechos humanos. Una aproximación a la Convención Internacional sobre los Derechos de las personas con Discapacidad. Madrid: Ediciones Cinca

Palacios, A. y Romañach, J. (2006). El modelo de la diversidad. La Bioética y los Derechos Humanos como herramienta para alcanzar la plena dignidad en la diversidad funcional. Madrid: Diversitas.

Pangalila, R. et al. (2015a). "Prevalence of fatigue, pain, and affective disorders in adults with Duchenne muscular dystrophy and their associations with quality of life". Archives of Physical Medicine and Rehabilitation, 96, pp. 1242-1247.

Pangalila, R. et al. (2015b). "Quality of life of adult men with Duchenne muscular dystrophy in the Netherlands: implications for care”. Journal of Rehabilitation Medicine, 47(2), pp. 161-166.

Peay, H. et al. (2015). "Prioritizing parental worry associated with Duchenne muscular dystrophy using best-worst scaling”. Journal of Genetic Counseling, 25(2), pp. 305-313. 
Peña, N. de la et al. (2017). "Influencia de los esteroides en los parámetros de la marcha de la distrofia muscular de Duchenne". Rehabilitación, 51(1), pp. 5-10.

Perumal, A. et al. (2015). Neuropsychological profile of Duchenne muscular dystrophy. Aplied Neuropsychology: Child, 4(1), pp. 49-57.

Read, J. et al. (2010). "Sleep and well-being in young men with neuromuscular disorders receiving non-invasive ventilation and their carers". Neuromuscular Disorders, 20, pp. 458-463.

Santofimio-Rojas, G. (2016). "De la anomalía a la discapacidad, una larga historia de exclusión social: de la muerte al destierro y el repudio, a la inclusión educativa”. Revista Inclusión \& Desarrollo, 3(1), pp. 34-46.

Shakespeare, T. y Watson, N. (1997). "Defending the Social Model”. Disability \& Society, 12(2), pp. $293-300$.

Simon, V. et al. (2011). "Duchenne muscular dystrophy: quality of life among 95 patients evaluated using the Life Satisfaction Index for Adolescents". Arq. NeuroPsiquiatr, 69(1), pp. 19-22.

Singh, R. et al. (2018). "Natural history of a cohort of Duchenne muscular dystrophy children seen between 1998 and 2014: An observational study from South India". Neurology India, 66, pp. 77-82.

Strehle, E. M. y Straub, V. (2015). "Recent advances in the management of Duchenne muscular dystrophy". Archives of Disease in Childhood, 100(12), pp. 1173-1177.

Thomas, P. et al. (2014). "Psychosocial challenges in family caregiving with children suffering from Duchenne muscular dystrophy". Health \& Social Work, 39(3), pp. 144-152.

Travlos, V. et al. (2017). "Quality of life and psychosocial well-being in youth with neuromuscular disorder who are wheelchair users: A systematic review”. Archives of Physical Medicine and Rehabilitation, 98, pp. 1004-1017.

Turabián, J. y Pérez-Franco, B. (2014). Viaje a lo esencial invisible: aspectos psicosociales de las enfermedades. Semergen: revista española de medicina de familia, 40(2), pp. 65-72.

Uzark, K. et al. (2012). "Health-related quality of life in children and adolescents with Duchenne muscular dystrophy”. Pedriatrics, 130(6), pp. e1159-e1566.

Vázquez-Cárdenas, N. et al. (2013). "Diagnóstico y tratamiento con esteroides de pacientes con distrofia muscular de Duchenne: experiencia y recomendaciones para México”. Revista de Neurología, 57(10), pp. 455-462.

Velarde, V. (2012). "Los modelos de la discapacidad: Un recorrido histórico". Revista Empresa y Humanismo, XV(1), pp. 115-136.

Velázquez, H. et al. (2013). "De la incapacidad a la diversidad funcional: Una mirada a la evolución histórica de los conceptos, significados e implicaciones para la intervención psicológica”. Informes Psicológicos, 13(2), pp. 79-101.

Vieitez, I. et al. (2017). "Espectro mutacional de la distrofia muscular de Duchenne en España: estudio de 284 casos". Neurología, 32(6), pp. 377-385.

Viñas, M. (2013). "Tratamiento en la distrofia muscular de Duchenne: fisioterapia respiratoria frente a nuevos avances". Fisioterapia, 35(1), pp. 32-39.

Walmsley, J. (2008). "Normalización, investigación emancipadora e investigación inclusiva en el ámbito de la discapacidad intelectual”. En L. Barton (comp.), Superar las barreras de la discapacidad. Madrid: Morata.

Wei, Y. et al. (2016). "Factors associated with health- related quality of life in children with Duchenne muscular dystrophy". Journal of Child Neurology, 31(7), pp. 879-886. 